\title{
Horizontes do corpo na escola: uma investigação sobre o Programa Escola Plural em Belo Horizonte $^{*}$
}

\begin{abstract}
Resumo: Discute as relacões entre um projeto políticopedagógico considerado inovador - o Programa Escola Plural, implantado na Rede Municipal de Ensino de Belo Horizonte a partir de 1995 - e as práticas corporais que acontecem no cotidiano de uma escola de ensino fundamental. Verificou-se, na escola pesquisada, uma significativa liberdade de movimentação corporal por parte dos alunos nos diferentes espaços de aprendizagem e a ausência de estratégias rígidas de controle do corpo. $A$ escola também apresenta expressiva abertura às dimensões estética e corporal do conhecimento, incorporando ao currículo formal práticas e saberes que costumavam ocupar tempos "marginais".
\end{abstract}

Palavras-chave: inovação pedagógica, escola plural, corpo, educação física.

Do ponto de vista da minha vivência como professora de Educação Física no ensino fundamental e como orientadora de estágio de licenciatura, tenho observado que há significativa dificuldade em vivenciar no dia-a-dia das escolas os ideais pedagógicos fundamentados nas concepções crítico-progressistas de educação e de Educação Física. Deparamo-nos freqüentemente com uma cultura fortemente sedimentada e refratária à mudança no que diz respeito aos conteúdos, às formas de organização das aulas, à relação com o conhecimento e ao próprio significado da Educação Física. O "isolamento pedagógico" a que nós, professores, somos submetidos pela fragmentação do conhecimento em grades/disciplinas curriculares constitui-se como barreira na medida em que confere a cada área de conhecimento códigos e estereótipos pouco flexíveis e, muitas vezes, inconciliáveis entre si nos processos de aquisição e construção do conhecimento.

* Artigo baseado na dissertação de mestrado intitulada "Corpo e movimento no cotidiano de uma Escola Plural", defendida em 2003 na Faculdade de Educação da UFMG, sob orientação da Professora Maria Alice Nogueira.

Movimento, Porto Alegre, v. 11, n. 3, p. 107-126, setembro/dezembro de 2005 
Com efeito, o que tenho constatado é que, a menos que as áreas de conhecimento - e, naturalmente, os professores - estejam integrados em torno de um projeto comum de educação, as tentativas de se desenvolver o trabalho pedagógico sob uma perspectiva crítica tendem a ser, pelo menos em parte, frustradas. Como enfatiza Arroyo (2001, p.15), faz-se necessário “... tentar superar as formas solitárias de organização do trabalho docente, em que cada um trabalha sua turma, sua matéria, seu horário, sem diálogo, sem possibilidades de trabalho coletivo."

A compartimentalização do conhecimento em disciplinas e a centralidade conferida aos pouco flexíveis conteúdos programáticos têm seu impacto também na relação dos alunos com seus próprios corpos, como aponta Gonçalves (1997, p.34):

A aprendizagem de conteúdos é uma aprendizagem sem corpo, e não somente pela exigência de o aluno ficar sem movimentar-se, mas, sobretudo, pelas características dos conteúdos e dos métodos de ensino, que o colocam num mundo diferente daquele no qual ele vive e pensa com seu corpo. $\mathrm{O}$ conhecimento do mundo é feito de forma fragmentada, abstrata, distribuído em diferentes disciplinas, limitadas a um horário prefixado e restrito.

O questionamento da organização rígida do ensino por disciplinas não é um fenômeno recente. Nos últimos anos, porém, a intenção de promover uma maior integração entre os diferentes saberes tem ganhado força. É possível perceber, nos sistemas escolares, sinais que apontam para uma maior flexibilidade nas aprisionadoras grades curriculares. ${ }^{1}$ No Brasil, especialmente a partir da década de 1990, a forma tradicional de organização escolar, que pouco se alterou ao longo do século XX, tem sido colocada em xeque em favor de práticas educativas que pretendem ser mais democráticas e socialmente inclusivas. Nesse contexto, Arroyo destaca a necessidade de se valorizar a pluralidade das potencialidades do desenvolvimento humano. Segundo ele,

[...] essas propostas pedagógicas inovadoras pensam em currículos, tempos e espaços e em profissionais que tentem dar conta da pluralidade da formação dos educandos: os valores, o conhecimento, a arte, a estética, a memória, a identidade, o sentimento, a emoção, as múltiplas linguagens. (ARROYO, 2001, p.15)

Com efeito, as diretrizes que norteiam as políticas educacionais inovadoras apresentam forte sintonia com as teorias críticas da Educação Física. Diante disso, creio ser possível pensar numa escola

1 Esta forma de expressão foi tomada do Prof. Miguel Arroyo, que costuma dizer, em palestras e conferências, que a educação encontra-se confinada atrás das grades (curriculares).

Movimento, Porto Alegre, v. 11, n. 3, p. 107-126, setembro/dezembro de 2005 
mais aberta para a vivência da "corporeidade/ movimentalidade", ${ }^{2}$ num contexto em que o movimento seja reconhecido como constitutivo do ser humano e de seus processos de aquisição e produção de conhecimento. Esta convicção levou-me a procurar, no seio das políticas pedagógicas consideradas inovadoras, indícios de mudança na relação instrumental que a escola tem estabelecido, ao longo dos séculos, com a corporeidade de seus alunos.

O Programa Escola Plural, projeto político-pedagógico da Rede Municipal de Ensino de Belo Horizonte, foi tomado como representante das propostas inovadoras de educação, constituindo-se como terreno de pesquisa.

\section{Escola Plural e inovação pedagógica}

Desde 1994, quando foi apresentado pela Secretaria Municipal de Educação de Belo Horizonte (SMED), o Programa Escola Plural vem convergindo olhares atentos de profissionais e pesquisadores ligados à educação. Esse interesse se justifica pelo fato de que o Programa propôs a instituição, nas escolas da Rede Municipal ${ }^{3}$ ( 170 estabelecimentos, na época), de uma série de mudanças pedagógicas - consideradas pelos próprios idealizadores como radicais - que desencadeariam um (já latente) processo de ruptura com as práticas pedagógicas tradicionais.

O Programa propôs alterações em tradições escolares sedimentadas, como conteúdos programáticos que atravessaram décadas, trabalho docente individualista e solitário; divisão do ensino em séries, bimestres e horas-aula tão familiares à cultura escolar. As alterações propostas refletiriam também em mudanças nas rotinas escolares e na relação professor-aluno, demandando do estudante uma outra forma de se relacionar com a escola, com o conhecimento, com as recompensas e sanções.

É a partir de severa crítica à estrutura tradicional do sistema escolar brasileiro e à sua incapacidade de atender às demandas da sociedade, somada à intenção de ressignificar a função sociocultural

2 Expressão utilizada por Valter Bracht (2001a).

3 A Rede Municipal de Educação de Belo Horizonte conta atualmente com cerca de 180 unidades escolares, 9 mil professores e 200 mil alunos, oferecendo atendimento em educação infantil, ensino fundamental, ensino médio, e as modalidades de educação especial e de jovens e adultos. Sua constituição remonta 1948 (quando foi criada a primeira escola municipal de Belo Horizonte), tendo apresentado expressivo crescimento nos últimos 20 anos (CASTRO, 2000; SMED, 2002).

Movimento, Porto Alegre, v. 11, n. 3, p. 107-126, setembro/dezembro de 2005 
do processo de escolarização, que o Programa Escola Plural se constituiu, com o claro intuito de promover uma intervenção radical na estruturação da atividade pedagógica. Seus eixos norteadores focalizam o papel da escola como espaço de vivência, construção e expressão da cultura e ressaltam a necessidade de que o currículo se abra nesse sentido. Reconhecem, também, a necessidade da integração do "coletivo da escola" na construção de uma nova identidade dos sujeitos envolvidos (BELO HORIZONTE, 1994, p.6-11).

A proposta de reorganização dos tempos escolares defendida pelo Programa busca redefinir a noção de tempo na escola, tendo o educando como eixo principal. Substitui a lógica seriada pela dos "ciclos de idade de formação", que têm como objetivo primordial dar mais flexibilidade aos tempos e conteúdos de aprendizagem, respeitando os diferentes ritmos dos alunos. Processos de formação plural são propostos como alternativa à concepção tradicional de ensino/aprendizagem - centrada na concepção transmissiva e cumulativa do conhecimento. A aprendizagem é entendida como um processo global, "onde os processos de conhecer e intervir no real não se encontrem dissociados" (BELO HORIZONTE, 1994, p.20). Contemplam, de forma especial, a importância da articulação da escola com a diversidade de dimensões da formação humana e propõem a organização do ensino por projetos de trabalho.

Atravessando toda a proposta da Escola Plural, está a intenção de construir de uma nova cultura escolar. A escola passa a ter sua função alargada, constituindo-se como "um espaço múltiplo, de diversidade, movimento e transformação", em que aprendizagem, socialização e vivências culturais não devem estar dissociadas (BELO HORIZONTE, 1996a, p.19-21). Nessa perspectiva, torna-se essencial proporcionar aos alunos tempos/espaços nos quais eles possam criar, debater idéias, posicionar-se, decidir, avaliar e criticar, possibilitando o desenvolvimento de suas capacidades para participar e intervir na vida social da comunidade.

As experiências vividas no cotidiano das escolas da Rede $\mathrm{Mu}-$ nicipal têm revelado múltiplas formas de apropriação das idéias da Escola Plural. Embora o projeto tenha sido oficialmente implantado em toda a Rede, a forma com que cada estabelecimento vem se apropriando dele articula-se com uma enorme gama de características que vão desde a história de vida dos sujeitos envolvidos às relações da escola com a comunidade.

A Escola Plural está atualmente no seu décimo primeiro ano de implantação e, do meu ponto de vista, encontra-se muito distante de alcançar, de forma abrangente, os objetivos a que se pro-

Movimento, Porto Alegre, v. 11, n. 3, p. 107-126, setembro/dezembro de 2005 
põe. O cotidiano das escolas tem revelado vários pontos de fragilidade do Programa e também sérios problemas de comunicação entre as instâncias e sujeitos envolvidos (escolas, Secretaria $\mathrm{Mu}-$ nicipal de Educação, Administrações Regionais, famílias, etc.) Algumas modificações implementadas recentemente são consideradas pelos professores da Rede como retrocesso, como, por exemplo, a extinção da carga horária semanal destinada à reunião pedagógica dos profissionais das escolas. A realidade da Rede Municipal mostra, hoje, uma "diluição" dos princípios do Programa, ou seja, a maioria dos estabelecimentos não se posiciona como "Plural", mas incorpora parcialmente alguns princípios e diretrizes, ao mesmo tempo em que se mostra resistente a outros.

Uma pesquisa realizada pelo Grupo de Avaliações e Medidas Educacionais da UFMG (GAME, 2000), identificou diversas dificuldades vivenciadas pelas escolas e famílias no processo de implantação do Programa. A maior parte dos aspectos apontados pelo GAME foram também percebidos por mim em relação à escola pesquisada. Dentre eles, destacam-se:

- dificuldade de ruptura com antigos referenciais impregnados na prática docente;

- carência de espaços de discussão pedagógica;

- problemas de diversas ordens (currículo, disciplina, organização pedagógica, etc.) gerados pela mudança no paradigma de avaliação e aprovação/reprovação; ${ }^{4}$

- dificuldades e tensões na relação família/escola no que diz respeito à assimilação das mudanças preconizadas pelo Programa;

- o "tateamento experimental" que caracteriza a prática de muitos professores, que se queixam da carência de referenciais curriculares mais claros e de um programa de capacitação mais efetivo para a categoria.

Por outro lado, uma série de aspectos detectados pelo GAME (2000) foram considerados como significativos avanços, entre os quais se destacam:

- a progressiva incorporação, pelas escolas, de uma cultura que favorece o debate e a busca coletiva de soluções;

4 O relatório do GAME destacou que "mesmo aqueles [professores] que defendem não-retenção, de acordo com o Programa Escola Plural, não conseguem ter argumentos fortes em defesa das irrefutáveis dificuldades que vêm enfrentando no diaa-dia da sala de aula." (GAME, 2000, p.113)

Movimento, Porto Alegre, v. 11, n. 3, p. 107-126, setembro/dezembro de 2005 
- maior consideração, por parte dos educadores, da realidade e dos interesses dos alunos na elaboração e desenvolvimento das aulas, contribuindo para a consolidação da posição destes como "centro da vida escolar";

- o estabelecimento de relações mais democráticas e horizontais entre os sujeitos no contexto escolar: diretores, professores, alunos, famílias, etc;

- percepção, por parte dos educadores, da necessidade de constante discussão dos conceitos de avaliação e aprendizagem;

- alargamento das possibilidades de inclusão de alunos que, por diversos motivos, encontravam-se excluídos do (ou dentro do) sistema escolar.

Charlot (2001) comenta que a democratização do acesso ao ensino torna a escola mais vulnerável às crises, pois cada vez que um país abre um segmento da educação às classes populares, abre a educação para novas contradições. A despeito de todos os entraves, dificuldades e erros estratégicos, o Programa Escola Plural é uma iniciativa que se propôs a encarar, com intrepidez, as crises e contradições a que Charlot se refere.

\section{Em busca de um corpo "plural"}

A partir do acompanhamento da experiência da Escola Plural, feito por intermédio de leituras e diálogos com colegas que lecionam em escolas da Rede Municipal de Belo Horizonte, fui conduzida a uma série de reflexões e questionamentos a respeito do "lugar" ocupado pelas práticas corporais - e pela Educação Física enquanto componente curricular - no contexto de uma política educacional que se propõe a romper com a lógica tradicional de educação escolar.

Como já foi exposto anteriormente, o discurso que fundamenta a proposta pedagógica da Escola Plural aponta para uma educação comprometida com a emancipação do sujeito e o pleno exercício da cidadania, compromisso esse que deve impregnar a atividade educativa desde a organização do tempo até a seleção de conteúdos a serem abordados. Aponta também para a construção de uma escola configurada como tempo/espaço de vivência cultural e de produção coletiva.

$O$ caderno Escola Plural: Proposta Político-Pedagógica (BELO HORIZONTE, 1994, p.20), anuncia uma preocupação, por parte dos idealizadores do Programa, com a forma com que o corpo deve ser tratado pela escola:

Movimento, Porto Alegre, v. 11, n. 3, p. 107-126, setembro/dezembro de 2005 
O ritmo de nossas aulas é monótono, repetitivo, pouco ativo. Os alunos e alunas permanecem demasiado tempo inertes, parados olhando o quadro, copiando. Passam horas na mesma postura, nos mesmos espaços: na carteira, na sala de aula. [...] A educação dos corpos - não o seu adestramento e controle - merece maior atenção nos processos escolares. É uma das lacunas mais lamentáveis em nossa pedagogia. Recolocar o corpo na centralidade que ele tem na construção de nossa identidade e da totalidade da nossa cultura exige criatividade profissional de todos nós.

Na mesma direção, Arroyo $(2000)^{5}$ afirma que dar ao corpo centralidade no processo educativo é uma tarefa fundamental da escola e desafia os profissionais da educação básica - não apenas os de Educação Física, ressalta ele - a buscar estratégias para recuperar a corporeidade como elemento da formação humana.

Nos cadernos do Programa Escola Plural é explicitada a preocupação com a perda da função socializadora da escola e a necessidade de uma maior abertura do tempo e do espaço escolares para a incorporação de novas dimensões de formação e de vivência da cultura.

Encontra-se, também, em um dos documentos da Escola Plural, a afirmação de que "todo o sistema [da Escola Plural] está voltado para o aluno aprender saberes, crescer, desenvolver-se como sujeito sociocultural, na pluralidade de suas potencialidades humanas" (BELO HORIZONTE, 1996, p.3). Para Soares (2000), essa intenção se reflete no processo ensino-aprendizagem no sentido de uma extrapolação do âmbito da atividade intelectual (que recebe uma ênfase exacerbada no contexto escolar tradicional). A escola "passa a incluir outros aspectos, muitas vezes marginalizados na escola, tais como os processos corporais e manuais, os processos socializantes, a vivência cultural e a estética" (p.25). É nesta mesma perspectiva que Bracht (2001b, p.77) afirma a importância da educação estética ou da sensibilidade "como elemento importante do que poderíamos chamar criticidade". Ressaltando que a idéia de criticidade é muito centrada na idéia de razão (como dimensão intelectual), o autor acredita que tratar o corpo como "sujeito", englobando as dimensões estéticas e éticas, pode contribuir para reformulação do conceito de criticidade e alargamento do próprio conceito de razão.

Essa perspectiva remete a algumas perguntas que considero relevantes. Como uma escola que se organiza como "Plural" trata a corporeidade de seus alunos? Que concepções e práticas envolvem o movimento corporal nesse contexto? Quais as possíveis repercussões dos princípios e diretrizes da Escola Plural no ensino

5 Miguel Arroyo é um dos idealizadores do Programa Escola Plural.

Movimento, Porto Alegre, v. 11, n. 3, p. 107-126, setembro/dezembro de 2005 
da Educação Física? Como a Educação Física tem se relacionado com as demais áreas do conhecimento e com a construção do projeto político-pedagógico da escola?

Optando pela metodologia do estudo de caso, elegi como terreno de pesquisa um estabelecimento escolar da Rede Municipal de Belo Horizonte que apresenta forte nível de adesão às diretrizes da Escola Plural. Mesmo ciente das limitações que permeiam a definição do grau de adesão dos estabelecimentos à Escola Plural, levei em conta, para efetuar a escolha, critérios que envolveram, além do auto-posicionamento da escola em adesão ao programa, aspectos como: formas de avaliação, a existência de projetos coletivos / projetos de ensino, a adesão à organização por ciclos e o tempo que é destinado na carga horária para discussão e produção coletiva dos docentes. ${ }^{6}$

A coleta de dados envolveu observação do cotidiano da escola durante aproximadamente seis meses (aulas de Educação Física, projetos, reuniões pedagógicas, entradas e saídas de turno e períodos de recreio), entrevistas (com professores, alunos e um membro da comunidade) e análise de documentos (em especial as publicações do Programa Escola Plural).

\section{Principais aspectos observados}

Após mergulho no cotidiano de um estabelecimento de ensino que se posiciona claramente como "Plural", posso dizer que uma série de aspectos observados no campo de pesquisa apontam para a construção de uma escola atenta à dimensão corporal de seus alunos e aberta ao envolvimento de práticas corporais em seu cotidiano. Destaco, abaixo, alguns elementos que, do meu ponto de vista, trouxeram subsídios para esclarecer as questões iniciais e, como não poderia deixar de ser, suscitar novas questões.

\section{Flexibilidade e autonomia na organização pedagógica}

As inter-relações entre a Escola Plural e as práticas corporais no estabelecimento escolar pesquisado podem ser detectadas a partir da sintonia que se manifesta entre as atividades observadas na escola e os princípios do Programa.

6 Esse processo de definição do estabelecimento a ser pesquisado se efetivou por meio de entrevistas com profissionais-gestores da Rede Municipal e pesquisa documental nos arquivos da Secretaria Municipal de Educação.

Movimento, Porto Alegre, v. 11, n. 3, p. 107-126, setembro/dezembro de 2005 
Nessa perspectiva, a flexibilidade e autonomia que foram atribuídas aos estabelecimentos escolares na organização da atividade pedagógica (currículo, funções desempenhadas pelos profissionais, gestão do tempo, etc.) cumprem um papel determinante. São condições fundamentais para a ruptura com práticas pedagógicas sedimentadas que se têm mostrado ineficazes diante das atuais demandas do sistema educativo, permitindo que a escola se liberte das amarras dos rígidos programas de ensino e possa organizar-se em torno de outros eixos. Permite, ainda, que o currículo se alargue no sentido de incorporar, legitimar e ser atravessado por práticas culturais novas ou que já aconteciam em tempos e espaços "marginais". Na escola pesquisada, uma maior abertura para a vivência de práticas corporais no espaço escolar pode ser encarada como parte desse processo. Estas práticas estão presentes em diferentes projetos interdisciplinares, em oficinas (dentro da grade curricular) e também em aulas de disciplinas como História, Português e Ciências. Vale registrar a opinião de uma professora a esse respeito:

Uma abertura sem volta, [...] porque inclusive o profissional que tem o prazer de fazer um trabalho assim dificilmente ele vai querer retroceder. Se ele sentiu prazer em trabalhar com as diversas dimensões da formação humana, e que o corpo, né, eu chamaria até de coluna vertebral disso, poderia chamar assim, né, como que ele vai voltar atrás?

Há que se considerar, porém, que a ausência de uma diretriz curricular no projeto político-pedagógico da escola faz com que muitas dessas práticas se percam em seu próprio experimentalismo, não tendo sua continuidade assegurada e gerando nos professores sentimentos de angústia e insegurança em relação aos caminhos trilhados.

\section{Os projetos no currículo da escola}

A organização do ensino por projetos é preconizada e defendida nas diretrizes do Programa Escola Plural. Na escola pesquisada, os projetos são como caldeirões em ebulição, em que são misturados, em caráter claramente experimental, uma série de ingredientes. A concepção de projetos na escola pesquisada é bastante ampla e bem diferente da perspectiva presente nas publicações da Escola Plural. Ao contrário do que é preconizado nos cadernos do Programa, nesta escola a maior parte dos projetos é idealizada por professores e/ou equipe pedagógica, sendo escassa a participação dos alunos nas etapas de problematização de temas e planejamento de ações. Entre os próprios professores é notória a carência de momentos de discussão e avaliação dos projetos implementados.

Movimento, Porto Alegre, v. 11, n. 3, p. 107-126, setembro/dezembro de 2005 
Todavia, ainda que, na escola pesquisada, os projetos se distanciem da idéia de "projetos de trabalho" defendida, entre outros, por Hernández e Ventura (1998), eles se mostram como espaço privilegiado de vivência e produção de práticas corporais, ao permitir que os temas tratados ultrapassem os campos estanques de transmissão de conteúdos e se materializem como síntese de vários saberes, mediados por diferentes linguagens.

Um dos tempos escolares onde o envolvimento da escola com atividades corporais e artísticas se manifestou expressivamente foi o projeto chamado Livre Escolha, considerado pela coordenadora pedagógica como "um dos carros-chefe da escola". O projeto se desenvolvia por meio de oficinas organizadas e oferecidas pelos professores (e também por moradores da comunidade), onde o aluno pode optar pelo tema de sua preferência. ${ }^{7}$ As oficinas aconteciam uma vez por semana, num horário unificado para todas as turmas do turno. De acordo com o relato elaborado pela escola (BELO HORIZONTE, 2000) o Livre Escolha é organizado da seguinte maneira:

Antes de iniciarmos o trabalho, fazemos uma sondagem junto aos alunos, para verificação da demanda. Com este levantamento em mãos, os professores montam suas oficinas e divulgam nas salas de aula, seja por meio de murais, livretos ou de cartazes. É um trabalho rico, de discussão

de objetivos e conteúdos das oficinas e de exercício de escolha. (p. 4)

De acordo com a equipe pedagógica da escola, “o desenvolvimento do trabalho permite que alunos de idades diferenciadas participem de uma mesma oficina, proporcionando interações cognitivas e sociais, o desenvolvimento da solidariedade e da autoestima, integrando as idades e os ciclos, constituindo-se, assim, novos agrupamentos." (BELO HORIZONTE, 2000)

Além do Livre Escolha havia, de acordo com a organização interna de cada ciclo, diferentes espaços abertos às práticas corporais. Havia, por exemplo, um projeto chamado Vivência Artística onde eram desenvolvidas (com carga horária quatro horas/ aula semanais) atividades corporais, musicais e plásticas. O projeto Qualidade de Vida articulava conhecimentos sobre o corpo com atividades corporais/ de lazer como ginástica, alongamento, relaxamento, jogos, esportes, etc. Outro projeto, chamado Recrea-

7 Alguns dos temas já desenvolvidos no Livre Escolha foram: Jogos e Brincadeiras, Fotolata, Construção de Maquetes, Dobraduras, Construção de Fantoches, Teatro, Coreografia, Capoeira, Culinária, Pintura, Hip-hop, Construção de Brinquedo com Sucata, Futebol, Grafite, Poesia, Cineclube, Rádio no Pátio, Jogos Dramáticos, Biodança, Flauta Doce, etc.

Movimento, Porto Alegre, v. 11, n. 3, p. 107-126, setembro/dezembro de 2005 
ção e Jogos, desenvolvia brincadeiras, jogos e incluía também algumas modalidades esportivas.

No caso dos projetos que tratam de temas da cultura corporal, percebeu-se um esforço no sentido de que a prática fosse articulada à abordagem de conhecimentos (técnicos, sócio-históricos, etc.) a respeito dos temas em questão.

Cada um dos ciclos tinha o seu Momento Coletivo, que funcionava da seguinte forma: uma vez por semana todas as turmas de um mesmo ciclo reuniam-se no auditório da escola para um evento, que na maioria das vezes envolvia uma apresentação artística (com produções da própria escola ou convidados) de música, ginástica, teatro, dança, etc.

Havia ainda na escola um grupo de teatro e outro de Hip-hop (dança e grafite), coordenados por pessoas da comunidade.

Nota-se, porém, que a continuidade dos projetos era constantemente ameaçada, seja pelo problema do absenteísmo docente, seja pela dificuldade de mobilização dos profissionais para discutir e avaliar o seu andamento. Mazzili (2000) observou conjuntura semelhante nas escolas pesquisadas pelo GAME:

A mobilidade de professores na unidade escolar, ora na substituição de professores faltosos, ora se envolvendo com questões administrativas em detrimento das questões pedagógicas foi apontada como fator que em parte levou os professores a abandonar o interesse pelo trabalho de pedagogia de projetos. A instabilidade da equipe reduz drasticamente as possibilidades de um trabalho continuado. (p.120)

Torna-se evidente a importância de que as escolas garantam momentos coletivos de reflexão, discussão e sistematização dos projetos que estão sendo realizados, uma vez que, como os próprios professores da escola pesquisada reconhecem, a ausência desses momentos compromete seriamente o trabalho pedagógico.

\section{O "clima da escola"}

O relatório do GAME $(2000),{ }^{8}$ ao comentar as transformações desencadeadas pelo programa escola plural, destaca que "Um fator imponderável é a mudança no clima da escola: som, risos e música,

8 O GAME - Grupo de Avaliação e Medidas Educacionais da FaE / UFMG, realizou (com apoio da Prefeitura de Belo Horizonte e da Fundação Ford), uma extensa investigação sobre o processo de implantação do Programa Escola Plural. O relatório final da pesquisa, denominado "Avaliação da Implementação do Projeto Político-Pedagógico Escola Plural", foi publicado em 2000.

Movimento, Porto Alegre, v. 11, n. 3, p. 107-126, setembro/dezembro de 2005 
movimentação de crianças nos pátios e corredores [...], o tratamento informal entre os alunos e o pessoal da escola." (p.6)

As observações do GAME sobre o clima das escolas "plurais" podem ser aplicadas à escola pesquisada. A liberdade de movimentação (e de expressão) corporal que os alunos possuem, tanto nos tempos intersticiais como nas atividades formais de aprendizagem apresentam clara sintonia com os princípios do Programa. A ausência das tradicionais filas (para entrar e sair da sala, após o recreio, etc.) nos ciclos iniciais do Ensino Fundamental, a autonomia de movimentação conquistada pelos alunos nas atividades dentro e fora de sala, a inexistência de "vigilância" nas entradas, saídas e no recreio são alguns aspectos significativos nesse sentido. Uma escola mais "encarnada", mais sensível à dimensão corporal dos alunos vem, de fato, sendo construída.

Outros aspectos associados ao clima da escola pesquisada que podem ser considerados como repercussões da Escola Plural como uma maior horizontalidade nas relações entre profissionais da escola e alunos (também apontada pelo GAME) e a autonomia delegada a estes últimos - podem ser relacionados à questão do corpo. Uma vez que a disciplina corporal é, historicamente, uma das formas preferenciais de exercício do poder e do controle não só no meio escolar como em outros contextos sociais, como mostra Foucault (1997) —, o abrandamento da necessidade de controle tende a repercutir em maior liberdade de movimentação corporal. Esse movimento tem sido percebido pelos professores como algo positivo, como revela a declaração de uma professora (ao comentar as transformações alavancadas pela Escola Plural):

Eu acho que os alunos estão sendo privilegiados. Porque se você for olhar pra trás, os meninos, eles eram muito assim... eles tinham que pedir bênção, eles eram dominados mesmo. Eles [os professores] não tinham essa questão do respeito pelo corpo do outro, pelo movimento. [...] Mesmo em sala de aula, o aluno era adestrado. Hoje os professores respeitam muito o movimento corporal da criança sem querer que o menino se comporte como um robô.

Quadros como esse são indicativos de que as escolas vêm atribuindo ao aluno, cada vez mais, uma posição de centralidade na vida escolar (GAME, 2000, p.65). Acredito que esse movimento se dá também no sentido de a escola encarar o aluno como "sujeito do presente", ou seja, estar mais atenta às características, às necessidades e à cultura própria das diferentes faixas etárias, contribuindo para que o processo de escolarização deixe de ser visto apenas como uma preparação para etapas futuras.

Movimento, Porto Alegre, v. 11, n. 3, p. 107-126, setembro/dezembro de 2005 


\section{Por uma formação "plural"}

Dayrell (1996, p.157) ressalta que "é necessário levar em conta o aluno em sua totalidade, retomando a questão do aluno como um sujeito sócio-cultural, quando sua cultura, seus sentimentos, seu corpo são mediadores no processo de ensino e aprendizagem."

Na mesma direção, os princípios e diretrizes da Escola Plural enfatizam a necessidade de que a escola seja concebida como espaço de socialização, não apenas no que tange às relações interpessoais, mas também no que diz respeito à construção de papéis, identidades e valores éticos. Nessa perspectiva, práticas, símbolos, rituais e hierarquias existentes na escola não devem ser encarados apenas como elementos que compõem o cenário da aprendizagem, mas como processos que são, em si, formadores (BELO HORIZONTE, 1994, p.20).

Pude perceber que este entendimento se faz presente entre os sujeitos do estabelecimento pesquisado, permeando o projeto político-pedagógico e conferindo à escola um ambiente favorável à construção de relações de solidariedade e respeito às diferenças.

A participação de alunos na definição das normas de convivência, na decoração das paredes dos pátios e na distribuição do material esportivo/recreativo utilizado no recreio são exemplos de iniciativas adotadas na escola e vistas por seus profissionais não apenas como estratégias de gestão escolar, mas como genuínos momentos de formação. Como ficou evidenciado ao longo da investigação, são expressivos os resultados alcançados, especialmente na forma de os alunos se relacionarem entre si e com o espaço físico da escola.

\section{As práticas corporais na hierarquia dos saberes}

Para Bracht (2001b, p.77),

A atual hegemonia do conhecimento científico na escola precisa ser flexibilizada para permitir que outros saberes se legitimem. Somente na medida em que se reconhecem como legítimos outros saberes que não os de caráter conceitual ou intelectual é que [nós, da Educação Física] temos uma chance de nos afirmarmos no currículo escolar.

O ensino centrado não em conteúdos, mas em vivências e habilidades, favorece a ampliação da compreensão do que sejam sa-

Movimento, Porto Alegre, v. 11, n. 3, p. 107-126, setembro/dezembro de 2005 
beres escolares. Traz para dentro do currículo diversas práticas que eram tradicionalmente marginalizadas, tratando-as "como conhecimentos legítimos e não um saber de enfeite, de tempos ociosos, de momentos de relaxamento para os educandos" (BELO HORIZONTE, s/d, p.25). Percebeu-se, porém, que na escola pesquisada as relações hierárquicas entre as diferentes áreas de conhecimento, permanecem, ainda que de forma atenuada.

Nesse sentido, não há como deixar de mencionar a questão da posição que a Educação Física, enquanto disciplina escolar, e as atividades que contemplam as dimensões "menos formais" do conhecimento, como a estética e a corporal, ocupam na hierarquia dos saberes escolares. Se, por um lado, é inegável a abertura do currículo no sentido de incluir, tangenciar e ser atravessado por estas práticas, por outro lado ficou evidenciado que elas podem ser preteridas em favor de outras consideradas mais importantes, como leitura, escrita e operações matemáticas.

Aparentemente, a maioria dos profissionais da escola acredita na importância das atividades lúdicas, corporais e estéticas no processo de aprendizagem e concorda com a necessidade de que a escola valorize essas linguagens. Porém, a questão da garantia de acesso ao conhecimento formal (ligado à cultura escrita) preocupa não só a eles como também aos pais dos alunos. Isso parece contribuir para que os conteúdos "formais" sejam priorizados. Isso ficou bastante claro após um longo período de greve, em que as atividades e projetos que privilegiavam as linguagens corporal e estética foram temporariamente suspensos. Sob a alegação de que era necessário minimizar o "prejuízo" acarretado pelos dias parados, optou-se por aumentar a carga horária de disciplinas como o Português e a Matemática.

\section{As aulas de Educação Física}

Dirigindo-se o foco para as práticas corporais como conteúdos específicos de uma área de conhecimento — a Educação Física —, surgem também questões relevantes.

A organização da Educação Física na escola pesquisada remete à questão da larga margem de autonomia que é conferida à escola e aos professores. O teor, a qualidade e até mesmo a existência da Educação Física dependem das decisões do grupo de professores de cada ciclo e, principalmente, do professor responsável pelas aulas.

Movimento, Porto Alegre, v. 11, n. 3, p. 107-126, setembro/dezembro de 2005 
A observação das aulas de Educação Física revelou que a incorporação dos princípios do Programa Escola Plural por essa disciplina não acontece de forma efetiva. Possivelmente, o fato de a Educação Física permanecer, em grande medida, desvinculada do projeto pedagógico da escola (especialmente no que diz respeito ao trato com o conhecimento), contribui para que isso aconteça.

Acredito que o entendimento tanto das mudanças quanto das resistências às mudanças no contexto da Educação Física passa pelo processo histórico que resultou na inserção desta disciplina no contexto escolar. A gênese da Educação Física como disciplina escolar está ligada a uma idéia fragmentada de ser humano: corpo e intelecto tratados separadamente pela escola. Dessa forma, os conteúdos que foram "escolarizados" pela Educação Física assumiram, historicamente, um caráter eminentemente prático, geralmente prescindindo do conhecimento e da reflexão sobre os movimentos e atividades vivenciados. Na escola pesquisada, foi possível perceber que a idéia de Educação Física no imaginário da maior parte dos professores, ligada à noção de mera atividade física ou recreativa, apareceu como empecilho para que a disciplina avançasse em direção ao que é preconizado pelo Programa Escola Plural.

Em relação à inserção do professor de Educação Física no cotidiano escolar, na Escola Municipal Horizontes foram observados alguns aspectos significativos. Pode-se dizer que a organização por ciclos e a flexibilidade da grade curricular enfraqueceram as "identidades de área" dos docentes. Antes da implantação da Escola Plural, na maioria das escolas da Rede Municipal os tempos de reunião pedagógica eram organizados de acordo com as áreas de origem dos professores: grupo de Educação Física, de Matemática, de Geografia, etc. Após a implantação do Programa, os ciclos passaram a ser a referência principal de organização do trabalho pedagógico. Talvez essa mudança de paradigma possa ter contribuído para a "desmobilização" da Educação Física como área de conhecimento, pois reduziu as possibilidades de os professores da área desenvolverem um trabalho articulado, trocarem experiências ou mesmo definirem um projeto de Educação Física para a escola.

Entretanto, do meu ponto de vista, houve também repercussões positivas. No caso da escola pesquisada, percebe-se que a organização por ciclos favoreceu um maior engajamento dos professores de Educação Física nas discussões pedagógicas, na definição das estratégias de organização e avaliação do processo educativo, nos conselhos de classe, etc.

Movimento, Porto Alegre, v. 11, n. 3, p. 107-126, setembro/dezembro de 2005 
Creio que isso representa um avanço em relação à situação observada por Jeber (1996), em pesquisa realizada na mesma Rede de Ensino, em que os professores de Educação Física apresentavam uma "identidade isolada" nas escolas, não tinham participação efetiva nos conselhos de classe e, em muitos casos, sequer freqüentavam a sala dos professores. Vejo com otimismo essas mudanças, pois acredito que uma maior integração do professor de Educação Física com seus colegas de outras áreas tende a ser rica em possibilidades de trabalhos conjuntos, de troca de idéias e experiências e de novas aprendizagens, para ambas as partes.

\section{Questões para reflexão}

Penso que o momento atual é crucial para a Educação Física. Num contexto em que esta disciplina corre riscos de desenraizamento ou mesmo de exclusão da cultura escolar, ${ }^{9}$ é fundamental que sejam delineadas estratégias político-pedagógicas para a atuação dentro desse espaço - que vem sendo redimensionado a partir dos novos ordenamentos legais da educação e de propostas como a Escola Plural.

A forma de organização da escola pesquisada e as próprias diretrizes do Programa Escola Plural conduzem a uma discussão da qual não se pode fugir: a questão da organização dos saberes escolares em disciplinas. Em um momento em que a flexibilidade curricular e a integração de diferentes saberes vêm se impondo como direção a ser tomada em face das atuais demandas educacionais, é necessário que a Educação Física problematize o seu "lugar" na escola. Como ressalta Bracht (2001a, 2001b), essa é uma questão fundamental para a sobrevida da Educação Física no contexto escolar.

Até que ponto é necessário considerar a especificidade didáticometodológica das diferentes áreas de conhecimento no momento de se planejar ações pedagógicas? Como deve ser tratada a especificidade de cada área num contexto em que se busca romper com as fronteiras entre os diferentes componentes curriculares? Creio que essas questões devem ser pensadas tanto no dia-a-dia das escolas quanto no âmbito da formação de professores para o Ensino Básico.

9 A respeito dos fatores que põem em risco o caráter e a existência da Educação Física na escola (exclusão pelas "brechas" da lei, descaracterização, terceirização) ver Vago (1999).

Movimento, Porto Alegre, v. 11, n. 3, p. 107-126, setembro/dezembro de 2005 
Bracht (200la, 200lb) afirma que os fatores que contribuíram, ao longo do tempo, para legitimar a presença da Educação Física nos currículos escolares já não se sustentam nos dias atuais, o que o leva a afirmar que esta disciplina, em situação de "orfandade", atravessa um momento de ruptura. "Um modelo, um ciclo que se fecha", ressalta o autor, propondo um desafio: "ousemos reformular nossas relações com o campo pedagógico na esteira das modificações em curso neste campo e no plano sócio-cultural mais geral." (200la, p. 9-10). Para Bracht (200la, p.9), uma interação mais intensa com o campo pedagógico é uma tarefa que se impõe, nos dias atuais, à Educação Física. "Uma relação que busque ou ouse também colocar uma outra direção em termos de proposição de temas e problemas - qual seja, da Educação Física para a Pedagogia", ressalta ele.

A observação das aulas na escola pesquisada revelou que a Educação Física, enquanto disciplina curricular, ainda permanece desvinculada das grandes questões e desafios que a escola tem enfrentado. Todavia, foi detectado um maior engajamento do seu profissional nas discussões coletivas, o que parece promissor no sentido de possibilitar um relacionamento mais estreito da área com o campo pedagógico, conforme é proposto por Bracht.

Creio que a Educação Física tem possibilidades de contribuir para a construção de uma escola mais atenta à dimensão corporal de seus alunos. O trato com o movimento corporal não deve, de modo algum, continuar a ser terreno exclusivo deste componente curricular. Acredito, entretanto, ser fundamental que a Educação Física - tanto no contexto disciplinar como nas ações interdisciplinares, projetos coletivos, etc. - consolide sua atuação como área de conhecimento que possui um objeto de estudo específico.

As leituras, os questionamentos e as experiências vividas durante a elaboração dessa pesquisa reforçaram meu entendimento de que é necessário que a Educação Física amplie sua "interface" com as demais áreas e com o campo pedagógico de uma forma geral, porém sem abrir mão da sua especificidade.

Movimento, Porto Alegre, v. 11, n. 3, p. 107-126, setembro/dezembro de 2005 


\begin{abstract}
Body horizons at school: a investigation about the 'Escola Plural' Program in Belo Horizonte

Abstract: Discusses the relationships between a political-pedagogical project considered innovative the 'Escola Plural' Program, implemented at the Education Network of Belo Horizonte since 1995 - and the corporeal practices which happen in the routine of a 'fundamental' school. What could be verified at the school under research was a significant freedom of corporeal movement by the students in different learning spaces and a lack of strict strategies of body control. The school also presents an expressive opening to esthetical and corporeal dimensions of knowledge, incorporating practices which used to occupy 'margi-
\end{abstract} nal' times to the formal curriculum.

Keywords: Pedagogical innovation, Escola Plural, body, Physical Education.

Horizontes del cuerpo en la escuela: una investigación
sobre el programa 'Escola Plural' en Belo Horizonte
Resumen: Este artículo discute las relaciones entre un
proyecto político-pedagógico considerado innovador-
el Programa Escola Plural, en ejecución en la red mu-
nicipal de Belo Horizonte desde 1995 - y las prácticas
corpóreas que suceden en la rutina de una escuela fun-
damental. Lo qué se puede verificar en la escuela
investigada es una significativa libertad del movimiento
corpóreo de los estudiantes en diversos espacios de
aprendizaje y una ausencia de estrategias rígidas del
control del cuerpo. La escuela también presenta
expresiva abertura a las dimensiones estéticas y
corpóreas del conocimiento, incorporando las prácticas
que ocupaban tiempos marginales al currículo formal.
Palabras-clave: Innovación pedagógica, Escola Plural,
cuerpo, Educación Física.

\title{
Referências
}

ARROYO, Miguel. Os movimentos sociais e a construção da concepção e prática da Educação Básica Universal (Minicurso). REUNIÃO ANUAL DA ANPED, 23, 2000, Caxambu. Notas.

Educação Popular com dignidade. Presença Pedagógica, Belo Horizonte, v.7, n. 41, p.5-17, set-out. 2001. Entrevista.

Movimento, Porto Alegre, v. 11, n. 3, p. 107-126, setembro/dezembro de 2005 
BELO HORIZONTE. Prefeitura Municipal. Escola Plural: Proposta Político-pedagógica. Belo Horizonte: SMED, out. 1994.

Ciclos de formação e trabalho coletivo dos professores. Belo Horizonte: SMED, 1996(a).

Proposta curricular da Escola Plural: referências norteadoras. Cadernos $\overline{E s c o l a ~ P l u r a l ~ n . ~ 2 . ~ B e l o ~ H o r i z o n t e: ~ S M E D, ~ s . d . ~}$

Terceiro Ciclo: um olhar sobre a adolescência como tempo de formação. Cadernos Escola Plural n. 5. Belo Horizonte: SMED, dez.1996 (b).

Avaliação na Escola Plural: um debate em processo. Cadernos Escola Plu$\overline{\mathrm{ral}}$ n. 6. Belo Horizonte: SMED, dez.1996 (c).

__. Rede de Trocas. Belo Horizonte: SMED, dez. 2000.

BRACHT, Valter. Pesquisa pedagógica em Educação Física: o estado da arte. CONGRESSO BRASILEIRO DE CIÊNCIAS DO ESPORTE, 12., 2001, Caxambu. Anais... Caxambu, CBCE, 2001 (a).

Saber e fazer pedagógicos: acerca da legitimidade da Educação Física como componente curricular. In: CAPARROZ, Francisco E. (Org.) Educaçáo Física escolar: política, investigação e intervenção. Vitória: Proteoria, 2001(b). p. 6779.

DAYRELL, Juarez. A escola como espaço sócio-cultural. In: (Org.) Múltiplos olhares sobre educação e cultura. Belo Horizonte: UFMG, 1996. p.136 161.

FOUCAULT, Michel. Vigiar e Punir. Petrópolis: Vozes, 1997.

GAME. Avaliação da implantação do projeto político-pedagógico Escola Plural. Belo Horizonte: GAME/FaE/UFMG, 2000.

GONÇALVES, Maria Augusta Salin. Sentir, pensar, agir: corporeidade e educação. Campinas: Papirus, 1997.

HERNÁNDEZ, Fernando; VENTURA, Monserrat. A organização do currículo por projetos de trabalho: o conhecimento é um caleidoscópio. Porto Alegre: Artes Médicas, 1998.

JEBER, Leonardo José. A Educação Física no ensino fundamental: o lugar ocupado na hierarquia dos saberes escolares. 1996. Dissertação (Mestrado em Educação) - FaE/ UFMG, Belo Horizonte.

LOURO, Guacira Lopes. Corpo, escola e identidade. Educação e Realidade, v. 25, n. 2, p.59-76, jul-dez. 2000.

MAZZILLI, Maria Aparecida. Dificuldades dos docentes na implementação de uma proposta inovadora - relato de um estudo. In: Singular ou plural? Eis a escola em questão. Belo Horizonte: GAME / FaE / UFMG, 2000. p.117-124

SOARES, Cláudia Caldeira. Construindo a Escola Plural: a apropriação da Esco-

Movimento, Porto Alegre, v. 11, n. 3, p. 107-126, setembro/dezembro de 2005 
la Plural por docentes de terceiro ciclo do Ensino Fundamental. 2000. Dissertação (Mestrado em Educação) - Faculdade de Educação, Universidade Federal de Minas Gerais, Belo Horizonte.

VAGO, Tarcísio. Início e fim do século XX: Maneiras de fazer educação física na escola. Cadernos Cedes. Campinas, n. 48, p. 30-51, 1999.

Anna Rachel Gontijo Mazoni Rua Conselheiro Lafaiete, 1925 / 1002

Bairro Sagrada Família Belo Horizonte - MG 31035-560

rachel@actar.com.br

** Professora da Fundação Helena Antipoffe da Universidade do Estado de Minas Gerais -UEMG.

Movimento, Porto Alegre, v. 11, n. 3, p. 107-126, setembro/dezembro de 2005 